\title{
Mantle wedge deformation by subducting and rotating slab and its possible implication
}

\author{
S. Honda ${ }^{1}$, Y. Orihashi ${ }^{1}$, K. Mibe ${ }^{1}$, A. Motoki ${ }^{2}$, H. Sumino ${ }^{3}$, and M. J. Haller ${ }^{4}$ \\ ${ }^{1}$ Earthquake Research Institute, University of Tokyo, Tokyo, Japan \\ ${ }^{2}$ Depertamento de Mineralogia e Petrologia Ignea, Universidade do Estado do Rio de, Rio de Janeiro, Brazil \\ ${ }^{3}$ Laboratory for Earthquake Chemistry, Graduate School of Science, University of Tokyo, Tokyo, Japan \\ ${ }^{4}$ Universidad Nacional de La Patagonia San Juan Bosco, Puerto Madryn, Argentina
}

(Received November 21, 2005; Revised April 5, 2006; Accepted April 10, 2006; Online published September 16, 2006)

\begin{abstract}
We have constructed a simple model of the deformation of the mantle wedge caused by the subducting and rotating slab based on corner flow model. By applying this model to the geological settings of the Somuncura plateau volcanic region, northern Patagonia, which is located far from the volcanic front, we constrain the mechanical aspect of the hypothesis that the volcanisms of the Somuncura region are triggered by the dehydrationinduced melting of the up-warped transition zone which may contain more water than other regions do. Assuming that the water concentrates in the transition zone under the Somuncura plateau, we find that the above scenario may be possible, if the speed of the subducting slab is less than $\sim 2 \mathrm{~cm} / \mathrm{yr}$ or the dip angle changes significantly ( $\sim 50$ degrees within $\sim 8 \mathrm{Myr})$.
\end{abstract}

Key words: Mantle wedge, rotating slab, volcanism, Somuncura, transition zone, water.

\section{Introduction}

Although most of the volcanisms occur near and along the plate boundaries, we also know the existence of volcanic activity far from the subduction zone and the ridge. It is common to attribute such activity to the hot spot or hot region (e.g., Morgan, 1971; Kay et al., 1993; Miyashiro, 1986). Meanwhile, recent experimental studies show that the $\beta$ phase (=wadsleyite) of olivine absorbs more water than other olivine polymorphs do (Inoue, 1994; Smyth and Kawamoto, 1997). This implies that the transition zone may be a possible water reservoir or sink in the mantle. Geophysical and geological implications of this inference may be quite important. For example, Bercovici and Karato (2003) argued that the transition zone may filter out the incompatible elements because of the dehydration-induced melting of the slowly up-going mantle through the transition zone.

If the water may be stored in the transition zone, it may become a possible trigger of volcanisms far from the subduction zone. Orihashi et al. $(2004,2005)$ studied the past volcanic activity of the Somuncura plateau, northern Patagonia, which is located about 300 to $650 \mathrm{~km}$ distant from the present volcanic front. They found that the age distribution of the Somuncura plateau volcanic rocks concentrates between $\sim 27$ to $\sim 20 \mathrm{Ma}$ and the older rocks distribute closer to the volcanic front than the younger ones (see below). De Ignacio et al. (2001) pointed out that this period almost coincides with a rapid rotation of the Fallaron-Nazca plates. Such a rapid rotation of plates may severely deform the sub-

Copyright (c) The Society of Geomagnetism and Earth, Planetary and Space Sciences (SGEPSS); The Seismological Society of Japan; The Volcanological Society of Japan; The Geodetic Society of Japan; The Japanese Society for Planetary Sciences; TERRAPUB ducting slab. De Ignacio et al. (2001) assumed a depression of the slab which may afford a space for the uprising asthenosphere and that the resultant intruded asthenosphere is the origin of the Somuncura volcanic activity. On the contrary, Orihashi et al. (2005) proposed an alternative hypothesis that the upward movement of the water-rich transition zone caused by the rotation of the slab surface and the subsequent dehydration-induced melting of the up-warped transition zone may be the origin of the above volcanic activity. This model is similar to the "wet" plume model proposed by Iwamori (1992) to explain the volcanisms in southeast Japan, although he did not mention where the water came from.

Since the upward flow should be present somewhere to conserve the mass, the hypothesis of Orihashi et al. (2005) should have some mechanism to explain the rare occurrence of such volcanic activity. Thus, in this paper we assume a non-uniform distribution of water and it may concentrate more under the continental area, as discussed later. Under this assumption, we apply our simple model to the mechanical aspect of their hypothesis and constrain the necessary condition for their hypothesis. The model is constructed to address the first-order question of the hypothesis, that is, the evaluation of two competing effects: the downward drag caused by the subducting slab and the upward rotation of subducting slab.

\section{Model}

Our model is a modification of the 2D corner flow (Batchelor, 1967; McKenzie, 1968) in which a constant viscosity fluid flows in a wedge-shaped region, as shown schematically in Fig. 1. Following Batchelor (1967) and McKenzie (1968), we use cylindrical coordinate to describe 


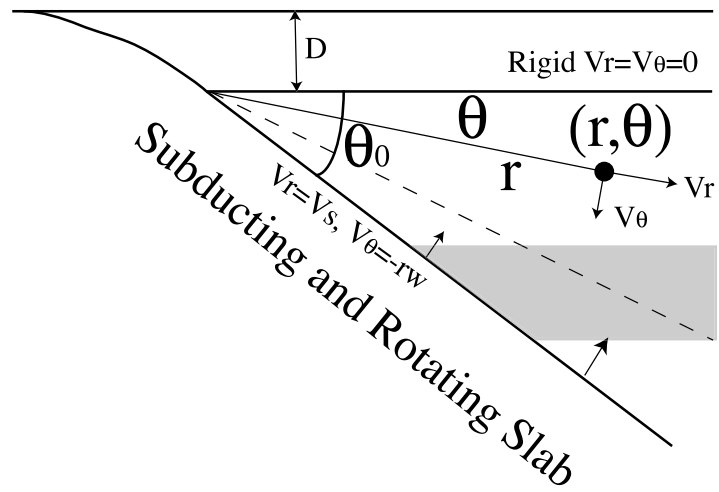

Fig. 1. Geometry of model. Mantle wedge is modeled by a corner flow, as described in Batchelor (1967) and McKenzie (1968). Shadowed zone schematically shows the area where the $\beta$ phase of olivine is stable.

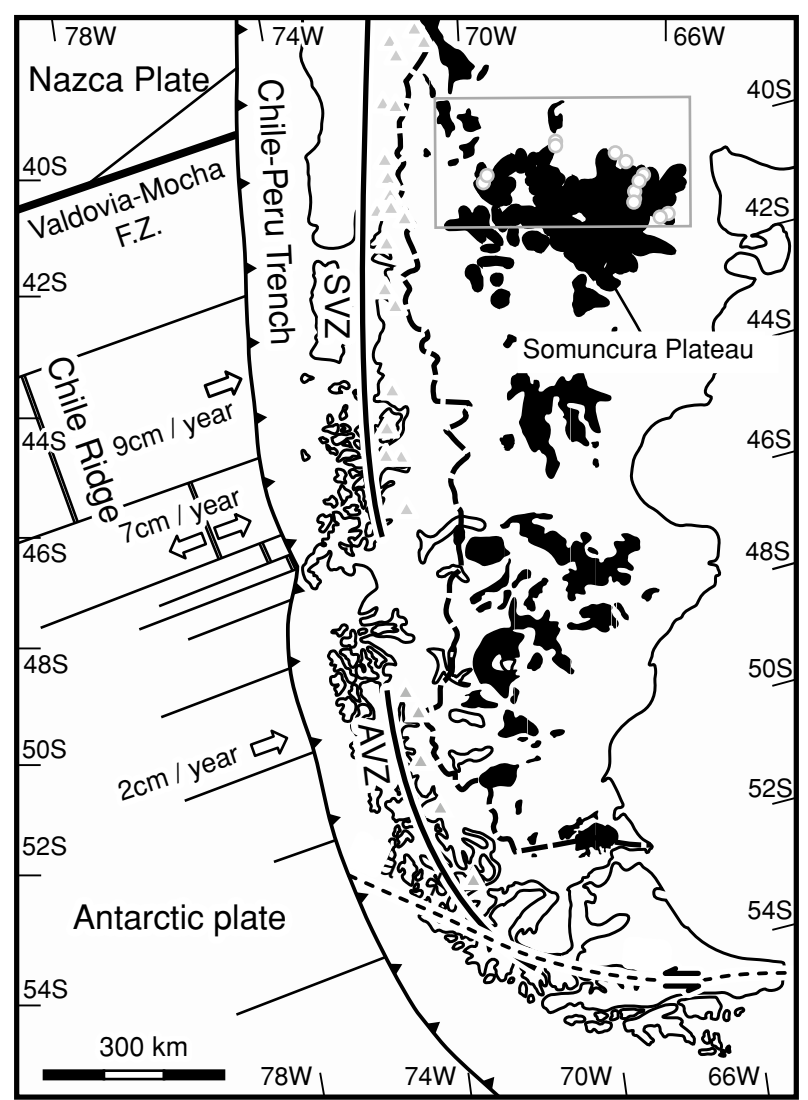

Fig. 2. Geological setting of the Somuncura plateau. Base map is simplified from the figure of Stern et al. (1990). Box shows a sampling area and the circles show the sampling sites of Stage I rocks. Filled region shows the distribution of the Cenozoic volcanic rocks. SVZ: Southern Volcanic Zone, AVZ: Austral Volcanic Zone, Thick lines: Limit of arc volcanism, Gray triangles: Recent volcanoes.

the problem mathematically. The origin of the coordinate is taken to be the axis of rotation and it is assumed to be located on the slab surface at the depth $D(=100 \mathrm{~km}$ : see Section 3 also). $r$ is the distance between the origin and the point considered and the angle $\theta$ is measured clockwise in Fig. 1. Under the assumption of incompressibility, the flow velocity may be represented by the stream function $\psi$ as

$$
v_{r}=\frac{1}{r} \frac{\partial \psi}{\partial \theta}, v_{\theta}=-\frac{\partial \psi}{\partial r},
$$

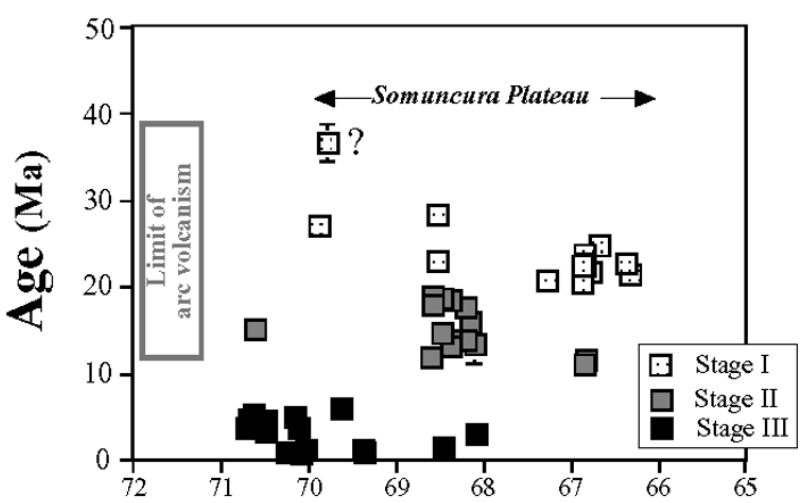

longitude (W)

Fig. 3. The age of volcanic rocks is shown along with the site location (longitude). (Modified from Orihashi et al. (2005).)

where $v_{r}$ and $v_{\theta}$ are the radial and angular components of the flow velocity, respectively. $\psi$ has to satisfy the biharmonic equation

$$
\nabla^{4} \psi=0
$$

which is derived from the conservation of momentum without the body and inertia forces.

The boundary conditions of the problem are

$$
\left\{\begin{array}{l}
{\left[v_{\theta}\right]_{\theta=0}=0,} \\
{\left[v_{r}\right]_{\theta=0}=0,} \\
{\left[v_{\theta}\right]_{\theta=\theta_{0}}=-r \omega} \\
{\left[v_{r}\right]_{\theta=\theta_{0}}=-V_{s}}
\end{array}\right\},
$$

where $\theta_{0}, V_{s}$ and $\omega$ are the angle of wedge (i.e. dip angle), the speed of subduction, and the angular velocity of the rotating slab, respectively. The solution to this problem may be obtained by the superposition of two types of flow, as

$$
\begin{aligned}
\psi= & \frac{r V_{s}\left[\left(\theta_{0}-\theta\right) \sin \theta_{0} \sin \theta-\theta_{0} \theta \sin \left(\theta_{0}-\theta\right)\right]}{\theta_{0}^{2}-\sin ^{2} \theta_{0}} \\
& +\frac{\omega r^{2}\left(\sin \theta \cos \left(\theta-\theta_{0}\right)-\theta \cos \theta_{0}\right)}{2\left(\sin \theta_{0}-\theta_{0} \cos \theta_{0}\right)}
\end{aligned}
$$

The first and second terms, respectively, represent the flow driven by the radial and rotational movement of the wall, that is, the slab surface (see Batchelor, 1967; McKenzie, 1968). Since the angle $\theta_{0}$ is changing with time, the above equations are supplemented by

$$
\theta_{0}=\alpha-\omega t,
$$

where $\alpha$ and $t$ are the initial angles of the wedge and time, respectively. The deformation of the horizontally layered structure mimicking the region of the $\beta$ phase of olivine is estimated by the movement of particles, which, initially, distribute on its top (410 km deep) and bottom $(550 \mathrm{~km})$ surfaces with a horizontal interval of $1 \mathrm{~km}$. The position of the particle is calculated by

$$
\frac{\mathrm{d} \underline{x}_{p}}{\mathrm{~d} t}=\underline{v}\left(\underline{x}_{p}\right)
$$

where $\underline{x}_{p}$ and $\underline{v}$ are the position vectors of each particle and the flow velocity at $\underline{x}_{p}$. This equation is integrated by the fourth order Runge-Kutta method. 


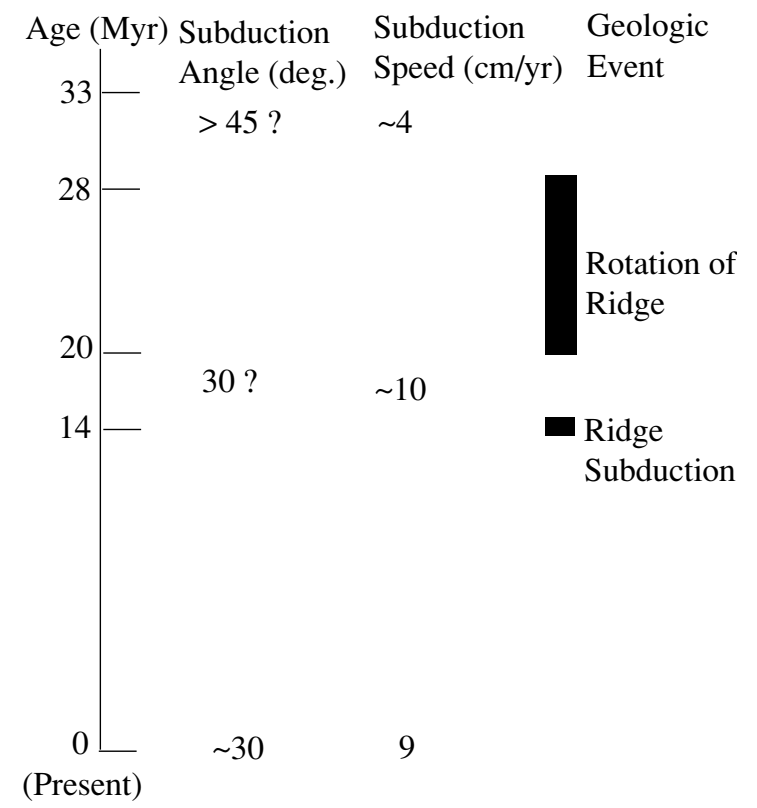

Fig. 4. Summary of tectonic setting around the Somuncura plateau. See text for detail.

\section{Possible Applications}

We apply our model to the Somuncura case and, thus, we briefly describe the geologic setting of the Somuncura area. Figure 2 shows the locality map around the Somuncra area. The K-Ar age data reported by Orihashi et al. (2004) in this area are compiled in Fig. 3. Based on the age and the characteristic of distribution of the rocks, Orihashi et al. (2004, 2005) newly classified them into three stages. Stage I ( $36 \sim 20 \mathrm{Ma})$ rocks constitute the Somuncura plateau and the rest of the stages (Stage II: $18 \sim 10 \mathrm{Ma}$; Stage III: $5.6 \sim$ $0.34 \mathrm{Ma})$ consist of the rocks after the formation of the Somuncura plateau. While the magma production of Stage I is voluminous (roughly $2,000 \mathrm{~km}^{3}$ ), a fairly small amount of magma production is inferred for the rest of the stages. Age data of Stage I show a hint of migration of the volcanisms from the volcanic front to the back-arc, and the opposite migration from the back-arc to the volcanic front in the later stages. Figure 4 shows a summary of tectonic history around the Somuncura area. From the study of the paleoreconstruction of the plate movements (Cande and Leslie, 1986; Tebbens et al., 1997), a drastic rotation of the ridge occurred between $\sim 28$ and $\sim 20$ Ma. During this tectonic event, we estimated that the convergence speed between the Nazca and South America plates changed from $\sim 4$ to $\sim 10$ $\mathrm{cm} / \mathrm{yr}$ based on their results. Another major tectonic event that occurred around this area was the subduction of the ridge at $\sim 14$ Ma (Tebbens et al., 1997; Cande and Leslie, 1986).

It is quite difficult to estimate the dip angle of the subducting plate in the past. However, we also have a hint of such estimates. The past volcanic front in Oligocene to Miocene overlaps the recent one (Rapela et al., 1988) but in late Oligocene ( $\sim 33 \mathrm{Ma})$ the volcanism temporarily spread to the fore-arc province (Muñoz et al., 2000), which suggests that the dip angle of the subducted slab might be larger at that time. Assuming that the position of the trench and the depth of the Wadachi-Benioff zone under the volcanic front are constant, we estimate a dip angle of $\geq 45$ degrees at that time.

In this paper, we shall only pay attention to the volcanic rocks between 27 and $20 \mathrm{Ma}$ of Stage I. The geochemical signature of rocks of other stages show a different spike of fluid-favor elements from that of Stage I rock, suggesting a different fluid origin (Orihashi et al., 2004, 2005). We are thinking that they were related to the subduction of the ridge and possibly an associated deformation of the transition zone, although we have no clear explanation for this stage. We neglect the 36 Ma rock of Stage I, since it is rather isolated from other Stage I rocks and, possibly, it is affected by excess $\mathrm{Ar}^{1)}$. If there is a clear genetic relation
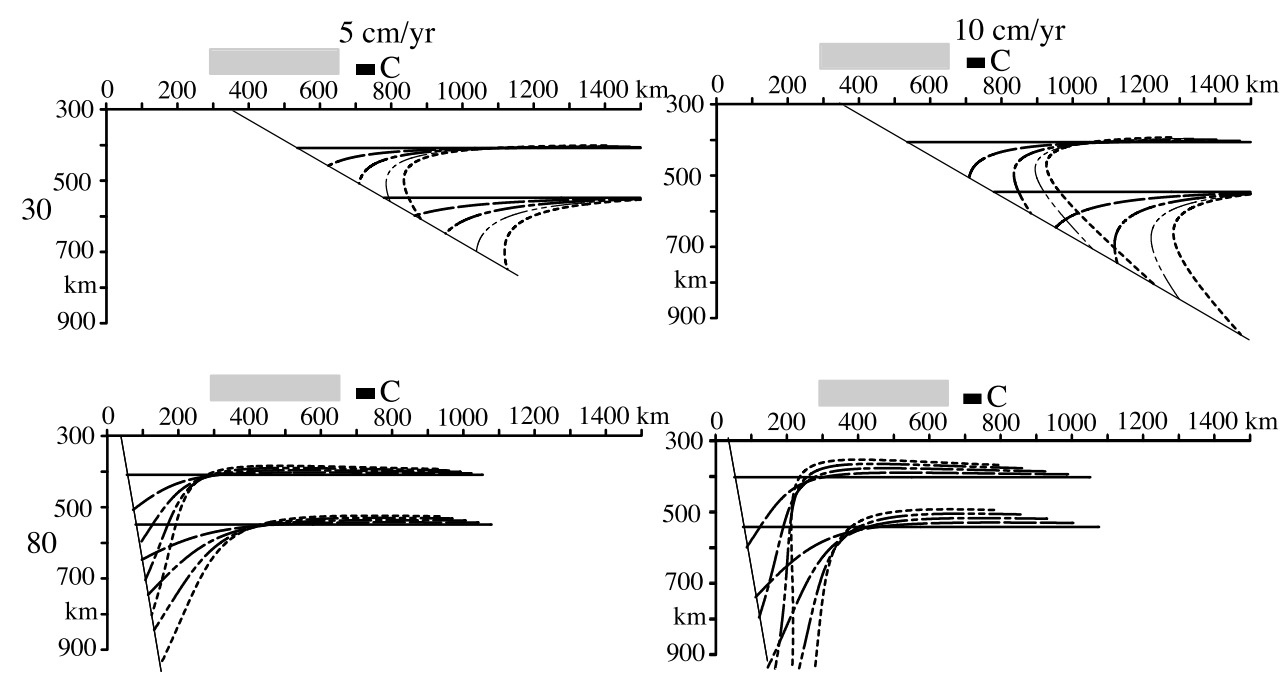

Fig. 5. Results of calculations without rotation of the slab. The abscissa is the horizontal distance from the axis of rotation (in this case, the volcanic front $)$ and the ordinate is the depth. Each column shows the same speed of subduction ( 5 and $10 \mathrm{~cm} / \mathrm{yr})$ and each row does the same dip angle ( 30 and 80 degrees). Thick solid, long dashed, one dot dashed, two dots dashed and short dashed lines correspond to the position of upper or lower surface of the region of the $\beta$ phase at 2, 4, 6 and 8 Myrs after the start of calculations. Thin lines show the positions of slab top surfaces. Shadowed zone shows an approximate position of the Somuncura plateau. Bar with "C" shows the approximate position of the east edge of the South-America continent. 
between this rock and the other rocks of Stage I, the present mechanism may not work, unless the speed of subduction is quite small.

Considering the complex geologic settings as described above, we have many unknown factors including a validity of 2D model. (We are thinking that the upward movement of the slab was caused by the deformation of the slab related to the rapid plate rotation. Thus, such a situation is 3D.) However, we believe that simple modeling provides a clue to constructing more complex models and a useful guide to understanding the data set.

As reference cases, we show the cases with timeindependent dip angles in Fig. 5 for four different dip angles. The shadowed region in Fig. 5 shows the approximate location of the Somuncura plateau. The distance is estimated by assuming that the axis of rotation of the slab coincides with the volcanic front. We have also studied the case with $D=0 \mathrm{~km}$, and found that the essence of the discussion given below is still valid, considering the ambiguity of the horizontal position of the Somuncura plateau with regard to the axis of rotation. In the real situation, the axis of rotation may correspond to the thickness of the overlying lithosphere. Thus, the choice of $100 \mathrm{~km}$ may be more reasonable. The time duration is 8 Myrs, mimicking the Somuncura case. From Fig. 5 and the following similar figures, we assume that the volcanism may occur in the area under which the deformed former upper surface of the transition zone goes above $410 \mathrm{~km}$. We notice that, even without the rotation of the subducting slab, the transition zone moves upward, especially if the dip angle is steep. If dehydration-induced melting occurs, this implies almost ubiquitous existence of melting. Since we do not see such a ubiquitous distribution of volcanisms on the surface, we need to explain why this is not the case.

Logically, there might be three possibilities: First, the melt cannot rise because it is denser than the surrounding mantle (Bercovici and Karato, 2003). Second, the water may not distribute uniformly in the transition zone. Third is the problem of modeling, such as the length of the actual slab is finite, 3D effects and the variable viscosity effects may play a role, and the top surface of the slab is not as flat as the present model assumes. As we mentioned in the introduction, we tentatively assume the second possibility in which water may be stored more under the continental area. This may explain the absence of volcanic activity in the back-arc side of the Somuncura plateau, and it may be also consistent with the absence of this kind of volcanic activity with the steep dip angle which is observed when the overlying lithosphere is oceanic.

Under this assumption, one may think that a constant steep dip angle case may explain the Somuncura plateau volcanisms. However, it cannot explain the migration of volcanisms toward the back-arc. The steep dip angle case rather shows an opposite migration. The migration toward the back-arc is better explained by the upward movement of the slab.

Figure 6 shows results with the rotation of the slab incorporated. As discussed above, we do not know how large the dip angle change was. (However, as discussed before, there is an indication of the change of dip angle.) We ten- tatively set the dip angle of the final stage to 30 degrees, which corresponds to the present subduction angle (Bohm et al., 2002). Probably, 30 degrees are near to the lower limit. The initial dip angle is changed from 45 to 80 degrees. Based on the results shown in Fig. 6, our preferred results showing the upward movement of the transition zone beneath the shadowed region and the landward migration of the deformation are those with a low speed of subduction $(\leq$ $\sim 2 \mathrm{~cm} / \mathrm{yr}$ ) or with a large change of dip angle (from 80 to 30 degrees within 8 Myrs). Our model predicts the continuous activity at the back-arc end of the Somuncura plateau. This point may be easily checked by field studies, i.e., older volcanics should be discovered beneath younger volcanics.

The preferred solution does not simply depend on the speed of the subduction and the angular velocity of the slab rotation. The position of the Somuncura also affects the results. As it approaches closer to the axis of rotation, the angle of rotation (or, the angular velocity) should be larger. This is because the upward velocity is proportional to the product of the radius and the angular velocity. Also, we should take into account the limited space of rotation (i.e., the total rotation angle should be, at least, less than 90 degrees within a limited period of rotation).

\section{Discussion}

The basic concept underlying in our model is the assumption of Orihashi et al. (2005) that the melt may be derived from the transition zone which was once in the $\beta$ phase of olivine. Density inversion of the melt is expected and has been experimentally found by Ohtani and Maeda (2001). Recent similar experimental works showed a possibility of melt entrapment on the top surface of the transition zone (Matsukage et al., 2005; Sakamaki et al., 2006) under certain conditions, which may support the model proposed by Bercovici and Karato (2003). However, even though the density-inversion occurs near the upper surface of the transition zone, the process of melt segregation and horizontal movement of the melt will control the subsequent behavior of the melt. If they are slow, the melt may be carried above the density cross-over depth.

The main supply of water to the transition zone may be the subducting slab in which some minerals can carry the water down to the transition zone, if the slab is cold enough (Komabayashi et al., 2004). Usually, the subduction occurs at the circumference of the continent, probably because of density and possibly rheological differences between the continental and oceanic lithosphere. Thus, it may be a reasonable expectation that there is more water in the transition zone beneath the continental area than beneath the oceanic area. The continental break-up may be initiated by the plumes (Storey, 1995) and they may carry the water-rich transition zone upward where plumes pass. Later, the mantle with less water content coming from below may take over the perturbed transition zone. As a result, we may expect richer water beneath the continental area (South America) and poorer water beneath the oceanic area (South Atlantic), which we assume in this paper.

The initial horizontal stratification of the transition zone assumed in this paper also depends on the water supply by the subducting slabs. It is probable that before the So- 

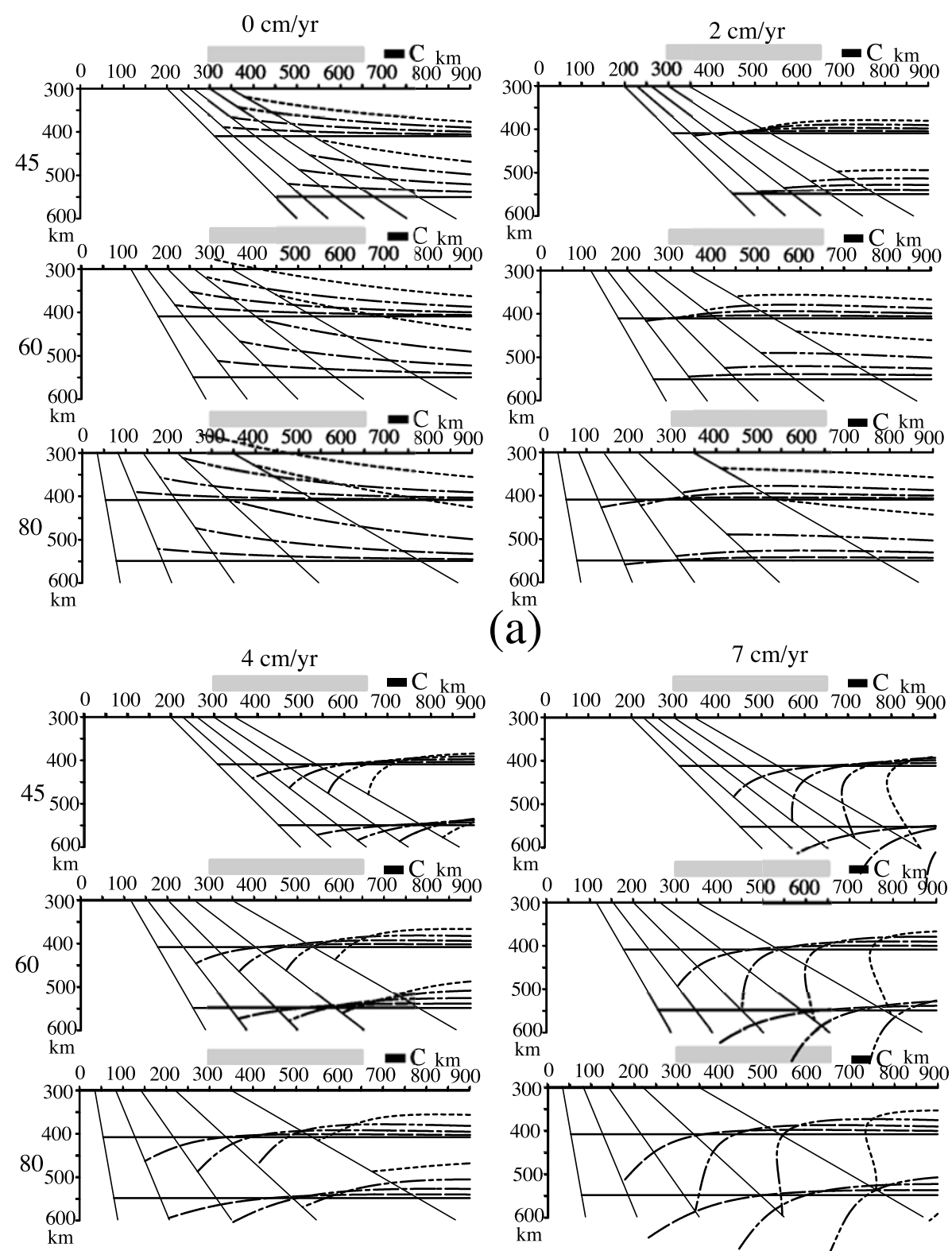

(a)

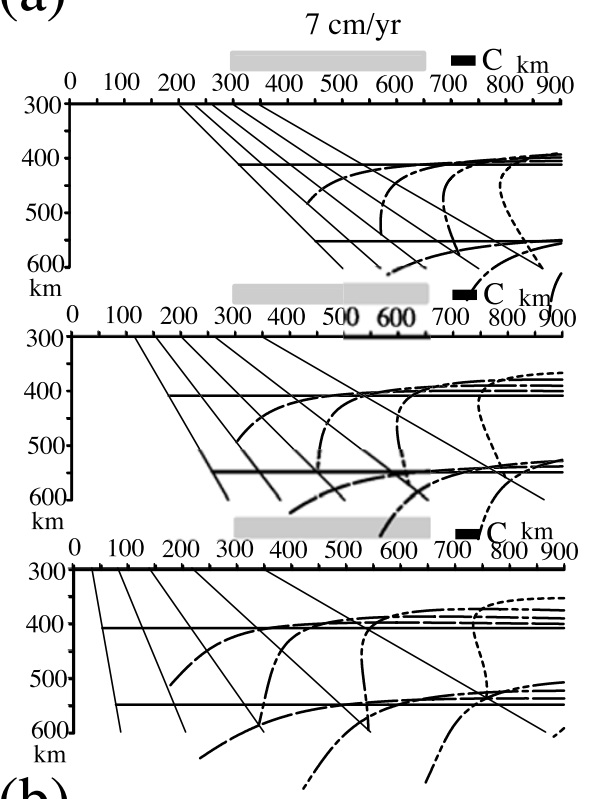

(b)

Fig. 6. Results of calculations with rotation. Each column shows the same speed of subduction ( 0 and $2 \mathrm{~cm} / \mathrm{yr}$ for (a) and 4 and $7 \mathrm{~cm} / \mathrm{yr}$ for (b)). Each row shows the same initial dip angle (45, 60 and 80 degrees for both (a) and (b)). Other symbols are explained in the caption of Fig. 5.

muncura volcanic activity, rather cold slab, i.e., old-aged slab, was subducting (e.g., Cande and Leslie, 1986). Later the slab became younger, implying that the water supply may have stopped. Our model is a simplified version of this situation.

The mechanism of water transportation is quite important in understanding the various water-related phenomena including our model and other types of volcanisms. Richard et al. (2002) found that the water distribution in the whole mantle is quite uniform, if we only assume that the diffusion and the advection by the convective flow are the only processes related to the transportation of water. Even if the transition zone has the capability of absorbing water, the water distribution is controlled by the advection because of the ineffectiveness of the diffusion process. They suggested another effective transportation mechanism such as perco- lation may be important. Thus, the mechanism of water transportation is still controversial, so that, in this paper, we took a fairly intuitive assumption as discussed above. To complete the model, it is definitely necessary to take this into account, but it is beyond the scope of the present work.

A constant viscosity model adopted in this paper implicitly assumes that the mantle wedge is well-mixed, thus nearly isothermal, that is probably a reasonable first-order approximation. However, we also admit that a temperature and pressure-dependent viscosity may affect the results. PTdependent viscosity will make the flow narrower and closer to the top surface of the subducting slab (see the results of, for example, Furukawa (1993). In such a case, the effects of the drag produced by the subducting slab on the mantle wedge may be localized near the subducting slab. Thus, we may expect that the mechanisms proposed in this paper may 
work more effectively. However, it is necessary to check this using a more elaborate model, but we also suspect that it is fairly difficult to make feasible models considering the present knowledge of geological settings, etc.

The main purpose of the application of our simple model is to constrain the necessary condition of the mechanical aspect of the hypothesis of Orihashi et al. (2005) and the main result is that the speed of subduction should be less than $\sim 2 \mathrm{~cm} / \mathrm{yr}$, or the change of dip angle should be large. As described before, we estimated that the relative motion between the Nazca and South America plates changed from $\sim 4$ to $\sim 10 \mathrm{~cm} / \mathrm{yr}$ during the rotation of ridge. This result implies that a considerable change of dip is necessary if our hypothesis is valid. However, we also think that the case of a small subduction velocity might occur under the situation of this drastic change of direction of the plate convergence. The stress produced by the drastic tectonic reorganization may temporary hinder the subduction. Such features may be preserved in the surface geology as a strong deformation of the overlying lithosphere.

The stagnated slab may also play a role since it is likely to induce the upward movement of transition zone above the stagnated slab. Zhao et al. (2004) found that the low-speed plume-like seismic velocity anomalies above the high-speed anomalies associated with the subduction of the Pacific plate in East China. This region corresponds to the active volcanic region far from the subduction zone. Although they proposed that the volcanic activity was triggered by the deep dehydration of the stagnated slab, this may be a result of the upward movement of the transition zone caused by the slab impingement.

Acknowledgments. We are grateful to H. Iwamori, D. Hirata, K. Nagao, R. Anma and other colleagues of the CHRISMASSY (Chile Ridge Subduction To Magma Supply System) Project Group for discussions and supports. Prof. E. Ohtani sent us his manuscript before its publication. We also thank J. Conder and anonymous referee for their constructive comments. A part of this research was supported by the fund from the Ministry of Culture, Sports, Science and Technology and the Japan Society for the Promotion of Science.

\section{References}

Batchelor, G. K., An Introduction to Fluid Dynamics, Cambridge Univ. Press, England, 655 pp., 1967.

Bercovici, D. and S. Karato, Whole-mantle convection and the transitionzone water filter, Nature, 425, 39-44, 2003.

Bohm, M., S. Luth, H. Echtler, G. Asch, K. Bataille, C. Bruhn, A. Rietbrock, and P. Wigger, The Southern Andes between $36^{\circ}$ and $40^{\circ} \mathrm{S}$ latitude: seismicity and average seismic velocities, Tectonophys., 356, 275-289, 2002.

Cande, S. C. and R. B. Leslie, Late Cenozoic tectonics of the Southern Chile trench, J. Geophys. Res., 91, 471-496, 1986.

de Ignacio, C., I. Lopez, R. Oyarzun, and A. Marquez, The northern Patagonia Somuncura plateau basalts: a product of slab-induced, shallow asthenospheric upwelling?, Terra Nova, 13, 117-121, 2001.

Furukawa, Y., Magmatic processes under arcs and formation of the volcanic front, J. Geophys. Res., 98, 8309-8319, 1993.

Inoue, T., Effect of water on melting phase relations and melt composition in the system $\mathrm{Mg}_{2} \mathrm{SiO}_{4}-\mathrm{MgSiO}_{3}-\mathrm{H}_{2} \mathrm{O}$ up to $15 \mathrm{GPa}$, Phys. Earth Planet. Inter., 85, 237-263, 1994.
Iwamori, H., Degree of melting and source composition of Cenozoic basalts in southwest Japan: evidence for mantle upwelling by flux melting, J. Geophys. Res., 97, 10983-10995, 1992.

Kay, S. M., A. Ardolino, M. Franchi, and V. A. Ramos, El origen de la meseta de Somuncura: Distribucion y geoquimica de sus rocas volcanicas maficas, Proceedings 12th Congreso Geologico Argentino, 4, 236 248, 1993.

Komabayashi, T. Omori, S. and S. Maruyama, Petrogenetic grid in the system $\mathrm{MgO}-\mathrm{SiO}_{2}-\mathrm{H}_{2} \mathrm{O}$ up to $30 \mathrm{GPa}, 1600^{\circ} \mathrm{C}$ : Applications to hydrous peridotite subducting into the Earth's deep interior, J. Geophys. Res., 109, B03206, doi:10.1029/2003JB002651, 2004.

Matsukage, K., J. Zhicheng, and S. Karato, Density of hydrous silicate melt at the conditions of Earth's deep mantle, Nature, 438, 488-491, 2005

McKenzie, D. P., Speculations on the consequences and causes of plate motions, Geophys. J. R. Astr. Soc., 18, 1-32, 1968.

Miyashiro, A., Hot regions and the origin of marginal basins in the western Pacific, Tectonophys., 122, 195-216, 1986.

Morgan, W. J., Convection plumes in the lower mantle, Nature, 230, 42 43, 1971.

Muñoz, J., R. Troncoso, P. Duhart, P. Crignola, L. Farmer, and C. R. Stern, The relation of the mid-Tertiary coastal magmatic belt in south-central Chile to the late Oligocene increase in plate convergence rate, Revista Geologica de Chile, 27, 177-204, 2000.

Ohtani, E. and M. Maeda, Density of basaltic melt at high pressure and stability of melt at the base of the lower mantle, Earth. Planet. Sci.Lett., 193, 69-75, 2001.

Orihashi, Y., A. Motoki, M. J. Haller, H. Sumino, H. Iwamori, F. D. Cario, D. Hirata, R. Anma, and K. Nagao, New geochronological and geochemical constrains for extra back-arc volcanism in Somuncura region, northern Patagonia, Abstracts IAVCEI, General Assembly 2004, S07C, 12, 2004.

Orihashi, Y., A. Motoki, M. J. Haller, and CHRISTMASSY Project Volcanic Group, Petrogenesis of relatively large-volume basalts on extraback arc province: Somuncura plateau, north Patagonia, Earth Monthly, 27, 438-447, 2005 (in Japanese).

Rapela, C. W., L. A. Spalletti, J. C. Merodio, and E. Aragon, Temporal evolution and spatial variation of early Tertiary volcanism in the Patagonian Andes, J. South American Earth Sciences, 1, 75-88, 1988.

Richard, G., M. Monnereau, and J. Ingrin, Is the transition zone an empty water reservoir? Inferences from numerical model of mantle dynamics, Earth Planet. Sci. Lett., 205, 37-51, 2002.

Sakamaki, T., A. Suzuki, and E. Ohtani, Stability of hydrous melt at the base of the Earth's upper mantle, Nature, 439, 192-194, 2006.

Smyth, J. R. and T. Kawamoto, Wadsleyite II: A new high pressure hydrous phase in the peridotite- $\mathrm{H}_{2} \mathrm{O}$ system, Earth Planet. Sci. Lett., 146, E9E16, 1997.

Stern, C. R., F. A. Frey, K. Futa, R. E. Zartman, Z. C. Peng, and T. K Kyser, Tarce-element and $\mathrm{Sr}, \mathrm{Nd}, \mathrm{Pb}$ and $\mathrm{O}$ isotopic composition of Pliocene to Quaternary alkali basalts of the Patagonian plateau lavas of southernmost of South-America, Contrib. Mineral. Petrol., 104, 294 308, 1990.

Storey, B. C., The role of mantle plumes in continental breakup: case histories from Gondwanaland, Nature, 377, 301-308, 1995.

Tebbens, S. F. and S. C. Cande, Southeastern Pacific tectonic evolution from early Oligocene to present, J. Geophys. Res., 102, 12061-12084, 1997.

Zhao, D., L. Jianshe, and T. Rongyu, Origin of the Changbai intraplate volcanism in Northeast China: Evidence from seismic tomography, Chin. Sci. Bull., 13, 1401-1408, 2004.

S. Honda (e-mail: honda@eri.u-tokyo.ac.jp), Y. Orihashi (e-mail: oripachi@eri.u-tokyo.ac.jp), K. Mibe (e-mail: mibe@eri.u-tokyo.ac.jp), A. Motoki (e-mail: motoki@uerj.br), H. Sumino (e-mail: sumino@ eqchem.s.u-tokyo.ac.jp), and M. J. Haller (e-mail: haller@cenpat.edu.ar)

1) We have, recently, found that this age is not affected by the excess Ar. However, we believe that this event is rather exceptional, considering the volume of erupted rocks. 